\title{
"Tudo por conta própria": autonomia individual e mediação técnica em aplicativos de autocuidado psicológico
}

\author{
"Everything by oneself": individual autonomy and technical mediation in \\ psychological self-care applications
}

\section{"Todo por uno mismo": autonomía individual y mediación técnica en aplicaciones de autocuidado psicológico}

\author{
Fernanda Glória Bruno ${ }^{1, a}$ \\ bruno.fernanda@gmail.com | https://orcid.org/oooo-0002-5950-7602 \\ Paula Cardoso Pereira ${ }^{1, b}$ \\ paula.cpereira@gmail.com | https://orcid.org/0000-0001-8947-9692
}

Anna Carolina Franco Bentes ${ }^{1, c}$

annacbentes@gmail.com | https://orcid.org/0000-0003-4167-6093

Paulo Faltay ${ }^{1, a}$

pfaltay@gmail.com | https://orcid.org/o000-0002-2467-1357

Mariana Antoun ${ }^{1, d}$

marianaantoun@ufrj.br | https://orcid.org/oooo-0002-7130-2781

Debora Dantas Pio da Costa ${ }^{1, c}$

deboradpio@gmail.com | https://orcid.org/o000-0002-8125-2650

Helena Strecker ${ }^{2, d}$

helenastrecker1@gmail.com | https://orcid.org/0000-0002-8487-0091

Natássia Salgueiro Rocha $a^{2, e}$

natassia.sr@gmail.com | https://orcid.org/oooo-0002-9692-1175

${ }^{1}$ Universidade Federal do Rio de Janeiro, Escola de Comunicação. Rio de Janeiro, RJ, Brasil.

2 Universidade Federal do Rio de Janeiro, Instituto de Psicologia. Rio de Janeiro, RJ, Brasil.

\footnotetext{
a Doutorado em Comunicação e Cultura pela Universidade Federal do Rio de Janeiro.

b Mestrado em Design Comunicacional pela Universidade de Buenos Aires.

c Mestrado em Comunicação e Cultura pela Universidade Federal do Rio de Janeiro.

d Graduação em Comunicação Social pela Universidade Federal Fluminense.

${ }^{d}$ Graduanda em Psicologia pela Universidade Federal do Rio de Janeiro.

e Tecnóloga em Produção Audiovisual pela Universidade Estácio de Sá.
}

\section{RESUMO}

Este artigo discute o resultado da análise de 10 aplicativos móveis de autocuidado psicológico utilizados no Brasil, que denominamos PsiApps. A análise se desdobra em duas camadas: uma 'visível', que envolve os discursos dos próprios aplicativos para descrever os problemas que visam solucionar, suas promessas e seus métodos; outra 'invisível', que inclui formas automatizadas de coleta e compartilhamento de dados dos usuários pelos aplicativos. Veremos como a ênfase na individualidade e na autonomia manifesta na primeira camada torna opaca uma série de mediadores presentes na segunda camada, em grande parte invisíveis para o usuário. O contraste entre a centralidade da agência individual promovida pelos discursos dos PsiApps e o caráter relacional da infraestrutura e do ecossistema de dados que os integram evidenciam as contradições da autonomia ofertada por esses aplicativos.

Palavras-chave: Aplicativos móveis; App Studies; Saúde mental; Subjetividade; Economia de dados. 


\section{ABSTRACT}

This article discusses the result of the analysis of 10 psychological self-care mobile applications used in Brazil, which we call PsiApps. The analysis unfolds in two layers: one, 'visible', involves the discourses employed by the applications themselves to describe the problems they seek to solve, their promises and methods; the other, 'invisible', includes automated ways of collecting and sharing user data by the applications. We will see how the emphasis on individuality and autonomy manifested in the first layer makes opaque a series of mediators largely invisible to the user present in the second layer. The contrast between the centrality of individual agency promoted by the discourses of the PsiApps and the relational character of the infrastructure and data ecosystem that they integrate highlight the contradictions in the notion of autonomy offered by these applications.

Keywords: Mobile applications; App Studies; Mental health; Subjectivity; Data economy.

\section{RESUMEN}

Este artículo discute el resultado del análisis de 10 aplicaciones móviles de autocuidado psicológico utilizadas en Brasil, que llamamos PsiApps. El análisis se desarrolla en dos dimensiones: una 'visible', que involucra los discursos de las propias aplicaciones para describir los problemas que buscan resolver, sus promesas y métodos; otra 'invisible', que incluye formas automatizadas de recopilar y compartir datos de usuario por las aplicaciones. Veremos cómo el énfasis en la individualidad y la autonomía manifestado en la primera dimensión vuelve opacos una serie de mediadores en gran parte invisibles para el usuario presentes en la segunda dimensión. El contraste entre la centralidad de la agencia individual promovida por los discursos de los PsiApps y el carácter relacional de la infraestructura y el ecosistema de datos que integran manifiestan las diversas contradicciones de la autonomía que estas aplicaciones ofrecen.

Palabras-clave: Aplicaciones móviles; App Studies; Salud mental; Subjetividad; Economía de datos.

Este artigo compõe o dossiê Comunicação, Saúde e Crises Globais: parte 2.

Contribuição dos autores:

Concepção e desenho do estudo: Fernanda Glória Bruno.

Aquisição, análise ou interpretação dos dados: Fernanda Glória Bruno, Anna Carolina Franco Bentes, Paulo Faltay, Paula Cardoso Pereira, Mariana Antoun, Helena Strecker e Natássia Salgueiro Rocha.

Redação do manuscrito: Fernanda Glória Bruno, Anna Carolina Franco Bentes, Paula Cardoso Pereira, Paulo Faltay e Mariana Antoun.

Revisão crítica do conteúdo intelectual: Fernanda Glória Bruno, Anna Carolina Franco Bentes, Paula Cardoso Pereira, Paulo Faltay, Debora Dantas Pio da Costa e Mariana Antoun.

Declaração de conflito de interesses: não há.

Fontes de financiamento: Conselho Nacional de Desenvolvimento Científico e Tecnológico (CNPq), Fundação Ford e Coordenação de Aperfeiçoamento de Pessoal de Nível Superior (Capes).

Considerações éticas: não há.

Agradecimentos/Contribuições adicionais: não há.

Histórico do artigo: submetido: 08 set. 2020 | aceito: 21 dez. 2020 | publicado: 22 mar. 2021.

Apresentação anterior: não houve.

Licença CC BY-NC atribuição não comercial. Com essa licença é permitido acessar, baixar (download), copiar, imprimir, compartilhar, reutilizar e distribuir os artigos, desde que para uso não comercial e com a citação da fonte, conferindo os devidos créditos de autoria e menção à Reciis. Nesses casos, nenhuma permissão é necessária por parte dos autores ou dos editores. 


\section{INTRODUÇÃO}

“Acreditamos num mundo onde o bem-estar emocional é uma simples escolha.” (Cíngulo)

Os aplicativos móveis (apps) relacionados à saúde (mobile health ou mhealth, em inglês) já pertenciam, antes da pandemia da Covid-19, a um campo em ampla expansão na economia da conectividade móvel. No espectro de aplicativos orientados para o bem-estar e para a saúde, observamos um crescente interesse por aqueles voltados à saúde mental e ao bem-estar psíquico (TOROUS et al., 2018), que são objeto deste artigo. A Apple, por exemplo, indicou o 'autocuidado' (self-care) como a grande tendência de aplicativos para o ano de 2018. Com a promessa de tornar os cuidados psicológicos mais acessíveis, estima-se que há mais de 10 mil aplicativos desse tipo disponíveis para download, número em constante crescimento (TOROUS et al., 2018).

Após decretar a pandemia do novo coronavírus, a Organização Mundial da Saúde (OMS) alertou que a saúde mental era um tema que merecia atenção e que o principal impacto psicológico da pandemia seria o aumento dos níveis de ansiedade e estresse. Um levantamento do mercado de dados móveis informa que, no Brasil, aplicativos categorizados como de 'saúde e fitness' tiveram um aumento de $226 \%$ em instalações não orgânicas (impulsionadas por anúncios) e de 116\% em instalações orgânicas (sem direcionamento de anúncios) no período entre 14 e 26 de março de 2020.

Tanto a expansão pela qual o setor já passava, quanto o crescimento exponencial no período de pandemia estão intrinsecamente relacionados à centralidade dos aplicativos na experiência conectada contemporânea (DAUBS et al., 2015). Atrelados a infraestruturas de dados e a modelos econômicos de plataformas digitais (ZUBOFF, 2019; SRNICEK, 2017), esses objetos técnicos alimentam mecanismos de coleta, armazenamento, análise, predição e uso de dados comportamentais.

Esse ecossistema digital entrelaça, de modo singular, corporações de tecnologia, ciência e sociedade em uma nova lógica que investe, cada vez mais, em processos algorítmicos de captura, análise e uso de informações psíquicas e emocionais extraídas de grandes volumes de dados. Tal investimento tecnocientífico, econômico e social compõe os processos de uma Economia Psíquica dos Algoritmos (BRUNO, 2018; BRUNO; BENTES; FALTAY, 2019), da qual os aplicativos fazem parte. Interessados em compreender como as informações psicológicas e emocionais vêm sendo coletadas e usadas em aplicativos móveis, nossa análise tem como foco o que designamos de 'aplicativos de autocuidado psicológico' ou, numa versão abreviada, PsiApps. Esta designação provém da análise do modo como os próprios apps enunciam o serviço que oferecem, bem como os estados de bem-estar psicológico que dizem promover.

Os PsiApps abrangem um escopo amplo e heterogêneo de serviços e funcionalidades relacionadas à saúde mental: vão desde técnicas de meditação, passando por controle do sono ou de outras funções emocionais e fisiológicas, até a realização de testes psicológicos e terapia guiada. Por um lado, esses apps têm o potencial de oferecer aos usuários informações e serviços, possibilitando acesso a dados em tempo real, orientações sobre condições clínicas e incentivo a hábitos benéficos à saúde psíquica, emocional e física. Por outro, eles ampliam potencialmente a coleta de informações psicológicas e emocionais, bem como as predições que se pretendem extrair dessas coletas que são valiosas não apenas para fins comerciais, mas também para a pesquisa médica, clínica e científica.

Nesta investigação, selecionamos 10 PsiApps disponíveis na Google Play Store (GPS), segundo critérios de relevância e popularidade no Brasil. Notamos que os discursos e as ferramentas ofertadas, o modo como enunciam o sofrimento psíquico, bem como a terapêutica proposta, estão fortemente centrados no indivíduo e em sua suposta autonomia. Neste artigo, questionamos o modelo de autonomia do indivíduo 
promovido e ofertado por esses PsiApps nos detendo em duas dimensões ou camadas: uma primeira, 'visível', que envolve os discursos dos próprios aplicativos para descrever os problemas que visam solucionar, suas promessas e seus métodos; uma segunda, 'invisível', que se dedica às formas automatizadas de coleta e compartilhamento de dados dos usuários pelos aplicativos.

Na primeira dimensão, identificamos que boa parte dos aplicativos dirige-se a um 'sujeito ansioso', ao qual oferecem meios para cuidar de si mesmo, especialmente através de um automonitoramento que promete autoconhecimento. O discurso identificado nessa camada reverbera uma série de processos relacionados à racionalidade e à subjetividade neoliberais, que envolvem "a pressuposição de um self autônomo, livre e com poder de escolha, como um valor, um ideal e uma meta" (ROSE, 2011, p. 211). Entendemos, assim, que os PsiApps reproduzem e reforçam essa racionalidade, instigando o usuário ansioso a resolver "tudo por conta própria" (CÍNGULO, 2019) e a tratar o bem-estar emocional como uma questão de "simples escolha" (CÍNGULO, 2019). Como veremos, essa oferta de autonomia e autocuidado individualizados e individualizantes nos apps analisados - que inclui desde ideais de empreendedorismo individual a modelos clínicos e psicológicos de autocuidado, aproximando-se de um treinamento de si - está repleta de mediadores invisíveis (LATOUR, 2012).

Na segunda camada, focalizaremos nesses mediadores invisíveis, evidenciando que o usuário não está apenas consigo mesmo nessa busca pelos estados emocionais prometidos; e tampouco está diante de uma ferramenta neutra. O usuário só está 'por conta própria' num sentido muito limitado do termo que, como veremos, não se confunde com a suposta autonomia e o controle sobre si alegados e propagados pelos PsiApps. Incorporados à própria materialidade e infraestrutura desses aplicativos, atuam uma série de mediadores pouco ou nada visíveis para o usuário: recursos das interfaces dos apps, mecanismos de coleta de dados, processos algorítmicos de análise e predição, entre outros. Usando estratégias metodológicas para a abertura dessas 'caixas-pretas' (LATOUR, 2012) que são os apps, exploramos dois níveis dessa segunda camada: os termos de uso e políticas de privacidade, de um lado; e, de outro, os rastreadores (trackers) presentes nos aplicativos, buscando pistas sobre os atores e mediadores presentes no ecossistema de dados dos PsiApps e seus modelos de negócios.

Por meio desse trajeto, evidenciaremos o contraste entre o que os PsiApps dizem ser - e também o que não dizem ser - e o que de fato são: objetos sociotécnicos atravessados por uma série de mediadores e que estão continuamente conectados a outros componentes, agentes e sistemas. Buscaremos assim apontar as contradições da autonomia, manifesta sobretudo no discurso dos PsiApps, centrado no indivíduo, em contraste com o contexto sociotécnico e histórico-cultural no qual estão inseridos. De um lado, tais apps reverberam processos de subjetivação neoliberais, que, a partir de modelos psicológicos e terapêuticos específicos, buscam responsabilizar os indivíduos na jornada do aprimoramento ininterrupto de si. De outro, embora reproduzam um discurso de suposta neutralidade e autonomia, os PsiApps contam para seu funcionamento com mediadores invisíveis, integrados às dinâmicas da economia digital, cada vez mais interessada em informações psicológicas e emocionais (BRUNO; BENTES; FALTAY, 2019).

Em uma perspectiva teórico-metodológica que se aproxima dos App Studies (GERLITZ et al., 2019; DIETER et al., 2019), pretendemos evidenciar e mapear a condição inerentemente relacional, híbrida e heterogênea desses dispositivos. Num contexto de crise e de extrema vulnerabilidade, é fundamental desvelar as relações inscritas em emergentes práticas de cuidado de si, discutindo e avaliando com cautela as 'soluções' ofertadas, uma vez que o acesso aos mediadores tradicionais ficou menos acessível durante a atual pandemia. Tradicionalmente realizadas por profissionais e em situações clínicas ou terapêuticas, as avaliações e os acompanhamentos de estados emocionais e psicológicos ganham nesse contexto um estímulo maior para a utilização de meios automatizados que dispensem o contato humano. Adiante, ex- 
ploramos as camadas 'visível' e 'invisível' dos aplicativos, fazendo com que certos aspectos da infraestrutura sociotécnica, normalmente invisíveis e/ou invisibilizados, tornem-se legíveis.

\section{APPS: METODOLOGIAS DIGITAIS E INFRAESTRUTURAS SOCIOTÉCNICAS}

Buscar e instalar aplicativos por meio das lojas de apps (app stores) se tornou uma ação corriqueira da nossa experiência digital. O que tende a permanecer pouco evidente é o fato de que aplicativos são pacotes de software que continuamente alimentam múltiplas conexões em uma infraestrutura multinível e multiescala, composta por uma miríade de atores heterogêneos - técnicos, econômicos, culturais, científicos, epistemológicos etc. Como os emergentes campos dos App Studies (GERLITZ et al., 2019; DIETER et al., 2019) e dos Software Studies (BRATTON, 2015) vêm demonstrando, aplicativos jamais são objetos autônomos e isolados, mas entidades relacionais, emaranhadas em infraestruturas de dados, modelos econômicos, conjuntos sociotécnicos, que operam em diferentes níveis.

Assim, ao interagir com qualquer objeto digital estamos imersos numa "estrutura de várias camadas de pilhas de protocolo de software em que as tecnologias de rede operam em uma ordem modular e interdependente" (BRATTON, 2015, p. xvii, tradução nossa). O que parece ser o uso individual, privado e frequentemente personalizado de um aplicativo é, na verdade, um agenciamento coletivo composto por uma cadeia de múltiplos atores, conexões e camadas continuamente atualizadas; uma rede complexa e heterogênea (LATOUR, 2012; LAW, 1992) de dispositivos móveis, interfaces, algoritmos, bases de dados, protocolos, rastreadores, grandes companhias de tecnologia, startups, parceiros comerciais e científicos, desenvolvedores, usuários etc.

Investigar os modos de funcionamento e as relações imbricadas nesses objetos técnicos é uma tarefa tanto promissora quanto repleta de obstáculos, uma vez que os apps, como a maioria dos dispositivos digitais e computacionais, tendem a se manter encapsulados em "caixas-pretas", dificultando descrevê-los e analisar seus efeitos (LATOUR, 2012; PASQUALE, 2015; LATOUR, 2000). No âmbito da Teoria Ator-Rede, essa noção é apropriada para designar o resultado do encapsulamento da rede heterogênea e dinâmica de atores e mediações que atuam na produção e manutenção de entes técnicos e de outros aparatos que, uma vez estabilizados, tornam opacas as relações e propriedades que os formam.

No ecossistema dos aplicativos há uma série de processos, componentes e conexões que ficam fora do campo de visibilidade dos usuários e cujo funcionamento raramente se torna explícito. Para abrir essas caixas-pretas e dar materialidade à dimensão relacional e infraestrutural encapsulada nesses objetos técnicos é preciso perseguir a dimensão agenciada deles, composta e heterogênea, tal como nos sugerem a Teoria Ator-Rede e os App Studies. Baseando-nos nas pistas metodológicas dessas abordagens, nos deslocamos por distintas camadas, níveis de escala e pontos de entrada dos PsiApps e de suas redes sociotécnicas.

Escolhemos a Google Play Store (GPS) para iniciar nossa análise, uma vez que 91\% dos celulares brasileiros utilizam o sistema operacional Android (PANORAMA MOBILETIME, 2019). Apesar de serem um "ponto de entrada" (p. 2) chave para os estudos multi-situados de aplicativos (DIETER et al., 2019), as possibilidades de busca e dados públicos disponíveis são extremamente limitados, uma vez que tais dados são em grande parte destinados a valiosas transações mercadológicas. A GPS não disponibiliza, por exemplo, o número exato de downloads dos aplicativos, nem uma separação desses downloads por país. Além disso, os resultados encontrados nas buscas diferem entre os usuários. Recorremos assim à versão gratuita da ferramenta App Annie para a elaboração de uma classificação de aplicativos a partir de critérios de relevância no contexto brasileiro.

i Ferramenta utilizada no mercado de desenvolvimento de apps para avaliação de performance e comparação com concorrentes. Cf. https://www.appannie.com/. 
Como os aplicativos de saúde mental não constituem uma categoria própria na GPS (logo, não poderiam ser diretamente pesquisados), elaboramos e comparamos dois levantamentos utilizando a busca do App Annie, selecionando aqueles que mantivessem vínculo com os problemas e processos visados na pesquisa:

1. O primeiro foi construído a partir de três rankings, usando as três categorias da GPS que mais se aproximam do campo dos PsiApps: estilo de vida, medicina e saúde \& fitness (lifestyle, medical e health \& fitness) ${ }^{\mathrm{ii}}$. Com base nisso, extraímos a lista de aplicativos que se encaixavam no critério da pesquisa, na mesma ordem em que aparecem na loja, quando o usuário navega entre as categorias;

2. O segundo teve como base a busca separada de cinco palavras-chave, resultando em mais cinco rankings: terapia, autoajuda, estresse, depressão e ansiedade. As palavras-chave foram definidas a partir de um levantamento prévio dos termos mais recorrentes nas descrições dos 100 primeiros aplicativos em cada uma das três categorias analisadas no primeiro levantamento.

Na sequência, selecionamos os 100 primeiros resultados das buscas por categorias e os 10 primeiros resultados das buscas por palavras-chave, somando um total de 350 resultados ${ }^{\mathrm{iii}}$. A partir desses levantamentos, tabulamos os resultados extraindo informações como o número de downloads exibidos na loja, total de comentários de usuários, nota, posição no ranking da categoria e posição no ranking por palavra-chave. Após a análise desses resultados, foram selecionados 10 aplicativos gratuitos que atendesse aos critérios:

3. De popularidade no Brasil: número de downloads, quantidade de avaliações (mais de cinco mil) e recorrência nas diferentes buscas, a partir da GPS do Brasil (organizada pela localidade, não necessariamente pelo idioma utilizado);

4. De relevância para a pesquisa: aplicativos que mencionavam em suas descrições formas de acompanhamento, apoio e/ou avaliação psicológicos, a partir de ferramentas de monitoramento de informações sobre estados psíquicos, humor e/ou emoções.

ii As categorias existentes na Google Play Store são predeterminadas e os desenvolvedores precisam enquadrar os aplicativos em apenas uma delas. Eventualmente a Google Play Store inclui/exclui categorias. As categorias podem ser alteradas e, de acordo com a GPS, elas "ajudam os utilizadores a pesquisar e descobrir as aplicações mais relevantes" (PLAY CONSOLE AJUDA, 2020).

iii Todas as buscas foram realizadas no dia 20 de agosto de 2019. O App Annie apresenta atualizações dos seus rankings em tempo real e permite realizar buscas em datas anteriores. 
Com base nesses critérios, os 10 aplicativos selecionados foram:

\begin{tabular}{|c|c|c|c|c|c|}
\hline & ÍCONE & NOME & ORIGEM & LANÇAMENTO & ID NA LOJA \\
\hline 1 & & Cíngulo: Terapia Guiada & Porto Alegre, Brasil & mar. 30, 2017 & com.cingulo.app \\
\hline 2 & & $\begin{array}{l}\text { Controle e Monitor: Ansiedade, } \\
\text { Humor e Autoestima }\end{array}$ & Pelotas, Brasil & jul. 27, 2018 & $\begin{array}{l}\text { com.twocatsapp. } \\
\text { dailyhumor }\end{array}$ \\
\hline 3 & & PsyTests & $\begin{array}{l}\text { Nova lorque, Estados } \\
\text { Unidos }\end{array}$ & dez. 29, 2016 & $\begin{array}{l}\text { ar.com.fennoma. } \\
\text { psicotest }\end{array}$ \\
\hline 4 & & Querida Ansiedade & Goiânia, Brasil & mar. 2, 2017 & $\begin{array}{l}\text { br.com.app. } \\
\text { gpu1622660. }\end{array}$ \\
\hline 5 & & Meditopia: Meditaçâo, Ansiedade & Istambul, Turquia & mar. 8, 2017 & app.meditasyon \\
\hline 6 & & $\begin{array}{l}\text { Lojong: Meditaçâo e Mindfulness. } \\
\text { Reduza ansiedade }\end{array}$ & Lisboa, Portugal & nov. 11, 2017 & br.com.lojong \\
\hline 7 & & Daylio - Diário - Controle de Humor & Bratislava, Eslováquia & ago. 17, 2015 & net.daylio \\
\hline 8 & & Monitor de Ansiedade e Humor & Fortaleza, Brasil & ago. 8, 2017 & $\begin{array}{l}\text { br.com.delxmobile. } \\
\text { ansiedade }\end{array}$ \\
\hline 9 & & $\begin{array}{l}\text { Sanvello for Stress, Anxiety \& } \\
\text { Depression }\end{array}$ & $\begin{array}{l}\text { Minneapolis, Estados } \\
\text { Unidos }\end{array}$ & jan. 25, 2015 & $\begin{array}{l}\text { com.pacificalabs. } \\
\text { pacifica }\end{array}$ \\
\hline 10 & & $\begin{array}{l}\text { Fabulous: Motive-me! Medite, } \\
\text { Relaxe, Durma }\end{array}$ & Paris, França & nov. 29, 2013 & $\begin{array}{l}\text { co.thefabulous. } \\
\text { app }\end{array}$ \\
\hline
\end{tabular}

Figura 1 - Ranking dos 10 aplicativos selecionados para análise Fonte: elaborado pelos autores.

A análise dos aplicativos selecionados para a pesquisa se desdobrou em dois eixos. O primeiro, voltado para a camada 'visível', dedicou-se sobretudo à análise do discurso dos desenvolvedores e divulgadores dos aplicativos através das descrições que utilizam na loja de aplicativos, sites e redes sociais das empresas. As questões que nos guiaram foram: como esses aplicativos enunciam os problemas que pretendem solucionar?; quais métodos e ferramentas propõem?; quais soluções prometem aos usuários? Essa camada reflete o tom publicitário com que os desenvolvedores pretendem atrair o usuário e muitas vezes é este o primeiro contato do usuário com o app. A análise desse primeiro eixo nos deu pistas importantes sobre as concepções de sujeito e de bem-estar psíquico que embasam as ferramentas propostas e refletem o imaginário dos desenvolvedores e de seus parceiros comerciais e científicos sobre como os aplicativos poderiam ser utilizados para promoção de saúde mental.

O segundo eixo analisado centrou-se na camada que permanece 'invisível' para a maioria dos usuários, visando avaliar as formas de coleta, o compartilhamento e os usos dos dados dos usuários. Que informações são coletadas? Quais as finalidades dessa coleta? Elas são compartilhadas com parceiros ou empresas não relacionadas diretamente ao serviço? Quem são esses outros agentes (os terceiros, utilizando a expressão usual contida nos termos de uso e nas políticas de privacidade)? Tais questões foram exploradas por meio da análise cruzada de dois objetos: a) os termos de uso e políticas de privacidade dos aplicativos; e b) os rastreadores (trackers) contidos em seus pacotes de instalação. 
Um tracker é um software cuja tarefa é coletar informações a partir do uso de um aplicativo. Ele pode informar ao desenvolvedor como o usuário utiliza o aplicativo e o dispositivo móvel, e geralmente é distribuído pelas empresas no formato SDK (Software Development Kit). Para detectar a presença desses rastreadores, utilizamos o serviço exodus, que se apresenta como uma plataforma de auditoria de privacidade para aplicativos Android e que dá visibilidade à presença de trackers através do rastreamento de seus arquivos ou pacotes de instalação. A identificação e análise dos rastreadores presentes nos PsiApps nos permite, assim, rastrear o fluxo de dados não declarados pelos desenvolvedores em seus termos de uso e políticas de privacidade, assim como os mediadores ocultos e os indícios dos seus modelos de negócios.

$\mathrm{Na}$ análise das duas camadas mencionadas, lançamos um olhar atento para as brechas e tensões que surgiam entre os diversos 'pontos de entrada', as dimensões de análise, os objetos e discursos pelos quais transitamos ao longo do trajeto investigativo: entre o modo como os aplicativos descrevem os problemas e como propõem solucioná-los; entre os discursos e atores visíveis e o rastreamento de atores invisíveis; entre o que enunciam e deixam de enunciar; entre os termos e políticas de privacidade e o que a inspeção dos rastreadores presentes nos pacotes de instalação evidencia etc. Tal análise desdobra-se por duas vias de questionamento. A primeira se desenrola em torno das camadas 'visível' e 'invisível', conforme viemos relatando; a segunda refere-se às tensões entre as dimensões 'individual' e 'relacional'.

Ou seja, nossa lente de análise percorrerá as ambiguidades e os conflitos entre as dimensões visível/ invisível e individual/relacional presentes em discursos e práticas, na materialidade e nas conexões dos aplicativos. Assim, veremos como a ênfase na dimensão individual, seja dos problemas visados, seja dos dados e informações capturados e analisados, mascara e contrasta com a natureza inerentemente relacional, mediada e heterogênea desses objetos. Uma articulação teórico-metodológica que nos ajuda a desvelar as diversas contradições do modelo de autonomia ofertado pelos aplicativos.

\section{AUTOCUIDADO COMO TREINAMENTO DE SI}

No âmbito da camada 'visível', a análise das descrições que os PsiApps fazem na GPS, em seus sites e nas redes sociais, permitiu observar algumas recorrências relacionadas a seus propósitos e suas funções. Classificamos, assim, o material em quatro principais categorias: a) problemas que pretendem solucionar; b) ferramentas que oferecem para tanto; c) promessas e soluções propostas; e d) modelos terapêuticos. Veremos a seguir como esses âmbitos se relacionam no que apontamos como o privilégio de um modelo de autocuidado voltado para um 'treinamento de si' tecnicamente mediado.

A respeito dos problemas, a ansiedade está no centro desses discursos, aparecendo em nove entre os dez aplicativos analisados, sendo que seis deles possuem a palavra 'ansiedade' em seus títulos ou subtítulosiv. A ênfase na ansiedade reverbera dados apresentados em relatório da OMS (WHO, 2020), que mostra que o Brasil lidera casos de ansiedade no mundo. Entre os problemas mais frequentes apresentados pelos PsiApps estão também estresse, depressão, questões relacionadas à autoestima, à atenção e ao foco e ao sono (Figura 2).

iv Controle e Monitor: Ansiedade, Humor e Autoestima; Querida Ansiedade; Meditopia: Meditação, Ansiedade; Lojong: Meditação e Mindfulness - Reduza a ansiedade; Monitor de Ansiedade e Humor; Sanvello for Stress, Anxiety \& Depression. 


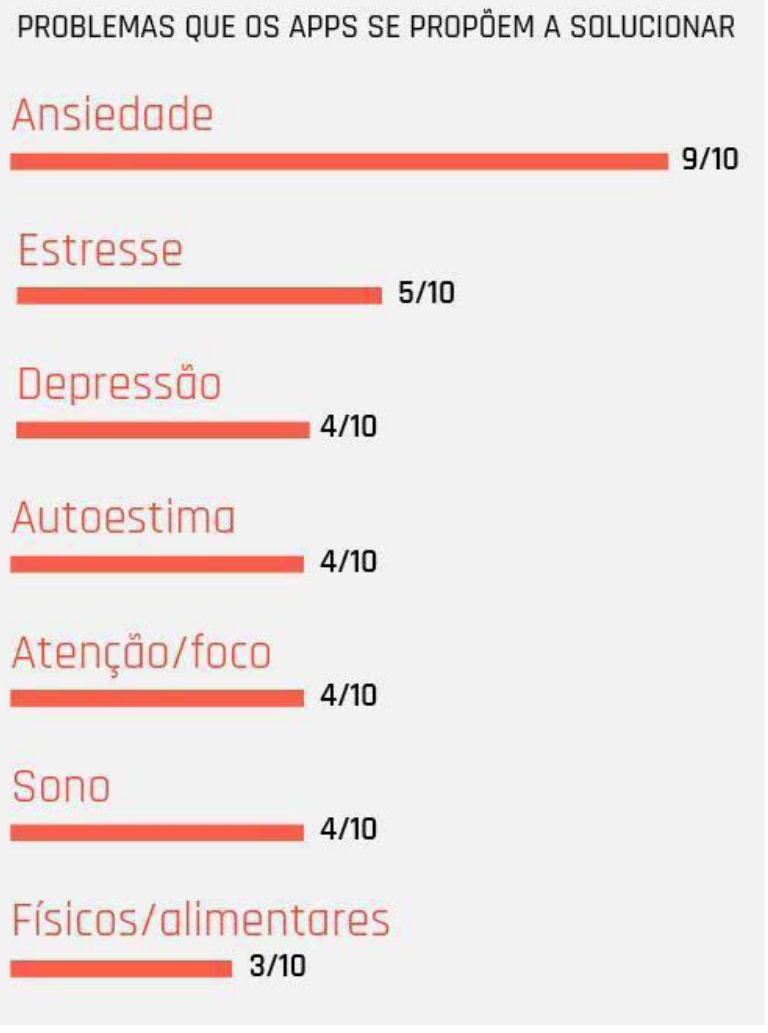

Figura 2 - Incidência dos problemas apontados pelos apps Fonte: elaborado pelos autores.

Alguns dos apps oferecem, inclusive, suas próprias definições de ansiedade. O Querida Ansiedade afirma que a ansiedade "é uma preocupação exagerada com aquilo que está por vir" (QUERIDA ANSIEDADE, 2019). Uma segunda definição é apresentada pelo Monitor de Ansiedade e Humor: "Ansiedade, ânsia ou nervosismo é uma característica biológica do ser humano e animais, que antecede momentos de perigo real ou imaginário, marcada por sensações corporais desagradáveis" (MONITOR DE ANSIEDADE E HUMOR, 2019). Em comum, os dois pontuam que a ansiedade é uma emoção normal e benéfica, sendo prejudicial, quando se torna muito recorrente e intensa. Assim, ambos oferecem meios de conviver de modo mais saudável com a ansiedade.

Para os PsiApps, em geral, a ansiedade não deve ser eliminada, mas sim administrada com a ajuda de suas ferramentas. Como enfatiza o Querida Ansiedade (cujo próprio título traz essa dimensão conciliatória), a ansiedade é "um alerta para a busca de uma vida mais autêntica" (QUERIDA ANSIEDADE, 2019). Nesse sentido, a ansiedade seria o fator pelo qual os sujeitos seriam impulsionados a cuidar, gerir e controlar a si mesmos.

Já em relação às ferramentas e aos métodos ofertados para auxiliar os usuários - a segunda categoria de nossa análise da camada 'visível' -, boa parte dos aplicativos atua numa zona nebulosa entre suporte técnico, apoio clínico e autocuidado. Essa indefinição é perceptível na descrição de alguns aplicativos: de um lado, ancoram seus serviços em conhecimentos e técnicas científicas e clinicamente estabelecidas; de outro, ressaltam que não pretendem oferecer serviço psicoterapêutico propriamente dito e que visam sobretudo oferecer meios para que o próprio usuário cuide, monitore e conheça melhor a si mesmo. Apenas dois dos dez aplicativos (Cíngulo e Sanvello) oferecem ferramentas de 'terapia guiada e/ou técnicas terapêuticas' enunciadas como clinicamente validadas.

Entre as ferramentas mais frequentes (Figura 3), além de exercícios de relaxamento, meditação guiada e respiração, estão recursos de 'automonitoramento'. Encontradas em sete dos dez aplicativos, 
tais ferramentas correspondem a técnicas para coleta explícita e direta de informações sobre humor e estados emocionais, indicando a relevância desse tipo de dado para os PsiApps. Outras funcionalidades complementam o automonitoramento, como ferramentas de diário pessoal e espaço para escrita terapêutica, ou ainda relatórios estatísticos e gráficos, voltados para visualização das análises dos dados fornecidos pelos usuários.

FERRAMENTAS E MÉTODOS OFERTADOS PELOS APPS

Exercícios e/ou atividades de relaxamento, meditaçăo guiada e respiraçăo

Automonitoramento

$7 / 10$

Materiais informativos ou de aconselhamento e/ou frases inspiradoras

Relatórios e gráficos estatísticos

$6 / 10$

Exercícios de Mindfulness

$4 / 10$

Exercícios para o sono

$4 / 10$

Diário pessoal, emocional ou escrita terapêutica $4 / 10$

Técnicas e/ou atividades específicas para crise de ansiedade e depressăo $3 / 10$

Testes psicológicos validados cientificamente $3 / 10$

Terapia guiada e/ou técnicas terapêuticas enunciadas como clinicamente validadas $2 / 10$

Figura 3 - Ferramentas e métodos ofertados pelos apps Fonte: elaborado pelos autores.

Em geral, as ferramentas de automonitoramento estão associadas à possibilidade de aprimorar o autoconhecimento e/ou melhorar a si mesmo. Essa possibilidade de autoconhecimento, de um 'aperfeiçoamento' de si, digamos, é encontrada em seis dos dez apps como a principal promessa - terceira categoria de análise da camada 'visível'. Há uma associação clara entre as práticas de automonitoramento rastreamento e registro de aspectos psicológicos e comportamentais, tais como humor, emoções, ansiedade, ânimo, atividades e outros - e o autoconhecimento, anunciado como chave para cuidar e melhorar a si 
mesmo. Como afirma o app Querida Ansiedade, o autoconhecimento serve para transformar "a vilã" ansiedade "em amiga" (QUERIDA ANSIEDADE, 2019).

A partir do automonitoramento sistematizado e de outros exercícios para reduzir a ansiedade, o autocuidado promovido pelos PsiApps se aproxima mais de um treinamento do que de uma hermenêutica de si, característica do modo clínico terapêutico moderno (FOUCAULT, 2010). Esse treinamento de si é expresso, por exemplo, na descrição do app Lojong, que se entitula "uma academia para mente" na qual "você aprende a treinar sua mente através de práticas de meditação" (LOJONG APP, 2019) e outros exercícios de relaxamento. Ou ainda, no discurso do app Fabulous: "iremos agir como seus treinadores da vida, construindo sua motivação para que você possa focar em desenvolver hábitos que reduzam problemas de saúde mental, como ansiedade, e melhorar sua produtividade diária” (FABULOUS, 2019).

O que a análise de tais discursos evidencia, portanto, é que o autocuidado, concebido como um 'treinamento de si', visa a um aperfeiçoamento, a partir de uma autogestão otimizada, monitorada e calculada que os apps proporcionariam. A mensagem aos usuários é a de que 'se conhecendo', eles podem se aperfeiçoar, o que reproduz e reforça aspectos de uma racionalidade neoliberal (ROSE, 2011; FOUCAULT, 2010; EHRENBERG, 2010; BROWN, 2006), centrada em soluções individuais, o que estimula os indivíduos a buscarem continuamente a otimização de seus recursos psicológicos.

Essa mensagem fica ainda mais evidente quando nos debruçamos sobre os modelos psicológicos e terapêuticos presentes nos discursos desses aplicativos. Convocada para conferir maior credibilidade e legitimidade aos PsiApps, uma série de abordagens, teorias e técnicas científicas e/ou clínicas específicas nos dão também algumas pistas sobre a concepção de bem-estar psíquico e emocional que esses apps subscrevem.

A influência da Psicologia Positiva e de suas técnicas de Coaching é facilmente percebida nos enunciados dos apps. Entre os aplicativos que mencionam modelos terapêuticos, o Mindfulness, que envolve técnicas e exercícios de direcionamento da atenção, é o mais recorrente. Traduzida para o português como 'atenção plena' ou 'consciência plena', o Mindfulness é uma técnica de meditação secular cujas práticas consistem em dirigir a atenção tanto para elementos externos, como sons e imagens, quanto para si próprio, como a respiração e as sensações corporais, com o objetivo de manter "afastados os demais pensamentos e os julgamentos" (MORAES, 2019, p. 234).

Para Ronald Purser (2019), aplicativos de atenção plena integram a 'McDonaldização do Mindfulness', uma vez que produzem uma técnica eficiente, escalável e quantificável e uma mercadoria globalizada e comercializável. Deste modo, junto com outros apps de controle do tempo e da atenção, os PsiApps compõem um mercado do 'sujeito ansioso', no qual pessoas buscam soluções rápidas e individualizadas para dar conta de sua ansiedade e de seus efeitos negativos no trabalho, nos relacionamentos e na saúde mental.

O discurso predominante dessa camada - na maneira como enuncia os problemas, ferramentas, resultados desejáveis e modelos de bem-estar - reverbera, assim, processos ligados ao neoliberalismo, bem como uma série de modelos clínicos, psicológicos e epistemológicos que alimentam e são alimentados por uma racionalidade neoliberal. O próprio modelo de autonomia promovido pelos aplicativos é, no entanto, contraditório ou paradoxal. Entendendo a autonomia como um dos objetivos e instrumentos da racionalidade e das estratégias neoliberais, o sujeito ansioso constrói uma relação subjetiva consigo que busca "um constante e intenso autoexame, uma avaliação das experiências pessoais, das emoções e dos sentimentos em relação a imagens psicológicas de realização e autonomia” (ROSE, 2011, p. 271).

\footnotetext{
v Segundo o Instituto Brasileiro de Coaching, o Coaching "é um processo, uma metodologia, um conjunto de competências e habilidades que podem ser aprendidas e desenvolvidas por absolutamente qualquer pessoa pra alcançar um objetivo na vida pessoal ou profissional, até 20 vezes mais rápido" (IBC, 2020). Autores como Dardot e Laval vêm enfatizando a relação entre técnicas como o Coaching e a programação neurolinguística e a produção do sujeito neoliberal, uma vez que elas "têm como objetivo fortalecer o eu, adaptá-lo melhor à realidade, torná-lo mais operacional em situações difíceis” (DARDOT; LAVAL, 2016, p. 333).
} 
Pressupondo que somos maus gestores dos nossos estados psicológicos (PURSER, 2019), os PsiApps se apresentam como a ferramenta ideal para gerirmos nossos níveis de ansiedade de forma supostamente autônoma, fácil e rápida, através de técnicas de treinamento de si que cotidianamente nos incentivam a atualizar o dispositivo com mais informações sobre nossos humores, emoções e estados psicológicos. O automonitoramento por meio dos PsiApps implica técnicas de registro e mensuração que promovem um autoconhecimento como objetivação de si em números, gráficos e estatísticas (NASCIMENTO, 2014). Desse modo, tal automonitoramento, anunciado como forma de conquistar autoconhecimento e bem-estar psíquico de modo autônomo, gera inúmeros dados sobre o usuário que, como veremos, fogem em grande parte do seu controle e conhecimento, pois é "Tudo por conta própria” (CÍNGULO, 2019), mas com o auxílio do app. Este, por sua vez, conta com uma série de atores e mediadores opacos que ultrapassam e influenciam a agência do usuário, sem que ele note.

Nesse processo, a figura do "sujeito empresarial" (DARDOT; LAVAL, 2016, p. 333) ou "self empreendedor" (ROSE, 2011, p. 215) emerge como aquele que se automonitora e quantifica ininterruptamente variações de humor, sintomas psicológicos e estados emocionais de modo a calcular, administrar e gerir seus problemas subjetivos. E é nessa retórica que se apoiam as funcionalidades desses aplicativos, uma vez que eles ofereceriam, ao alcance do usuário, as ferramentas necessárias para ele "superar os problemas emocionais que mais atrapalham a sua vida" (CÍNGULO, 2019).

No seio da cultura empreendedora neoliberal, cada um é, portanto, responsável por superar suas fraquezas e otimizar continuamente a si mesmo (ROSE, 2011; FOUCAULT, 2010; EHRENBERG, 2010). O automonitoramento, o cálculo e a quantificação constantes servem para avaliar frequentemente a performance (EHRENBERG, 2010) dos sujeitos empreendedores de modo a fornecer o conhecimento necessário para que eles ultrapassem dificuldades e fragilidades pessoais. Embora o discurso dos apps enfatize que o sujeito é responsável por seu sucesso (ou seu fracasso) e que ele é autônomo na conquista do seu bem-estar psíquico, numa espécie de "empreendedorismo psíquico" (FISHER, 2016, p. 137) tais promessas só podem ser alcançadas se os usuários estão assistidos pelas ferramentas dos próprios aplicativos, que envolvem uma série de processos opacos aos olhos dos usuários, ferindo, assim, sua suposta autonomia. Como afirma o Daylio/Diário, o aplicativo "agrupa humores e atividades para estatísticas e calendário para ajudá-lo a entender melhor seus hábitos" a fim de que o usuário "tenha o controle das suas atividades e crie padrões para se tornar mais produtivo!” (DAYLIO, 2019, tradução nossa)vi.

É curioso notar como essa versão tecnologicamente assistida do autocuidado opera uma série de inflexões neoliberais numa noção cujos sentidos históricos já foram tão distintos. Mais afastado de nós, o cuidado de si se constitui na Antiguidade como um conjunto de técnicas pelas quais a vida de cada um é tomada como objeto de conhecimento ou de arte (FOUCAULT, 2002). Mais recentemente, a noção de autocuidado tem uma trajetória médica e política que encontra uma de suas expressões mais potentes no feminismo negro entre os anos 1970 e 1980. O cuidado consigo ganha, nesse contexto, a força política de sobrevivência frente a instituições médicas racistas e sexistas, implicando ações tanto individuais quanto coletivas que envolviam, inclusive, a abertura de clínicas comunitárias (NELSON, 2011).

Toda essa dimensão política, crítica e coletiva é esvaziada na versão tecnoliberal do autocuidado encarnada pelos PsiApps. Na esteira das ferramentas de autoajuda, a retórica neoliberal do autocuidado adiciona uma atenção maior aos limites e às fragilidades individuais, buscando ao mesmo tempo aceitá-los e superá-los por meio de investimentos em si mesmo. Os PsiApps materializam, assim, o investimento e a

vi Assim como as categorias da GPS (tal como mencionado na nota 2 deste artigo), os títulos dos aplicativos também podem sofrer alterações a fim de otimizar a experiência de busca dos usuários e/ou por mudança na estratégia comercial dos produtos. Na data da busca realizada, o aplicativo ‘Diário' estava referido como ‘Daylio’ na GPS e, por sua vez, no AppAnnie. 
responsabilidade individuais como o caminho terapêutico para lidar com problemas psíquicos e emocionais sem considerar fatores coletivos, socioculturais e contextuais implicados no sofrimento individual.

Tal perspectiva está em consonância com o que Mark Fisher (2016) chama de "privatização do stress" (p. 125) ao abordar a saúde mental nas sociedades capitalistas atuais. A "privatização do stress" (p. 125) para o autor, foi parte fundamental do projeto de destruição do conceito de público e do qual depende, fundamentalmente, o conforto psíquico. Em nossa análise, chama atenção como os aplicativos raramente vinculam os estados de ansiedade a dimensões que ultrapassam o indivíduo. Para eles: “A melhor forma de aprender a lidar com a ansiedade é conhecer a si mesmo" (QUERIDA ANSIEDADE, 2019).

Ao propor ferramentas individualizantes para solucionar os problemas do 'sujeito ansioso', os PsiApps deixam a cargo do indivíduo o sucesso ou o fracasso de suas funcionalidades. Mas não são apenas os processos sociais, culturais e históricos que são invisibilizados pelo discurso dos aplicativos. Aos olhos dos usuários, a infraestrutura sociotécnica e seus modelos de negócios são ainda mais opacos. A retórica do automonitoramento atrelada às promessas de autoconhecimento estão também vinculadas ao interesse comercial dos apps e ao ecossistema de dados que os alimentam, como veremos a seguir.

\section{ABRIR A CAIXA-PRETA: EXPOR OS MEDIADORES INVISÍVEIS}

De um ponto de vista sociotécnico, como viemos destacando, um aplicativo é uma entidade relacional e agenciada de camadas de software (DIETER et al., 2019; BRATTON, 2015) e montada em tempo de execução (GERLITZ et al., 2019), uma vez que tanto o aplicativo como seu usuário estão sempre conectados a uma miríade de objetos, serviços, dispositivos e infraestruturas, sem que esse usuário saiba exatamente quando, como, onde e com quem tais conexões são estabelecidas.

Ao abrir um aplicativo, por exemplo, uma série de processos internos e externos ao dispositivo móvel é iniciada, como acesso às funções do sistema operacional e transferência de dados para servidores em nuvem. Assim, mapear e registrar essas conexões permite, entre outras finalidades, tornar visíveis as relações de poder e a economia de dados dos aplicativos, enfatizando sua relacionalidade e contingência (ZITTRAIN, 2008). São relações manifestas num modelo de negócios vinculado às grandes corporações de tecnologia, à extração ininterrupta de dados pessoais (ZUBOFF, 2019; SRNICEK, 2017) - o que exige uma atualização contínua dos aplicativos (NIEBORG; POELL, 2018).

Para acessar a rede de associações encapsuladas nos aplicativos e dar visibilidade aos múltiplos mediadores que sustentam o modelo de negócios no qual o aplicativo continuamente se atualiza e monetiza, é necessário acessar o que chamamos de camada 'invisível'. Importante sinalizar que essa invisibilidade não é absoluta nem uniforme, pois envolve dois estratos distintos: um intencionalmente invisibilizado, mas acessível (termos de uso e políticas de privacidade); e outro inerentemente invisível ao usuário comum (mecanismos automatizados de captura, processamento e compartilhamento de dados, entre outros).

Assim, para rastrear os fluxos de captura e compartilhamento de dados e os atores que compõem essa infraestrutura sociotécnica, examinamos num primeiro momento os termos de uso e políticas de privacidade, raramente lidos com atenção pelos usuários, mas centrais à delimitação da responsabilidade jurídica do aplicativo. Notamos que apesar de todos fazerem menção ao compartilhamento de dados com terceiros e de quase a totalidade admitir a coleta de informações pessoais e/ou de atividades do usuário (oito e nove apps, respectivamente), apenas quatro dos dez PsiApps são específicos sobre com quem compartilham os dados e apenas dois apps fazem referência ao tipo de dados que podem ser compartilhados. Isso é especialmente crítico pelo caráter sensível dos dados aos quais esses aplicativos têm acesso, uma vez que disponibilizam ferramentas de registro, análise e monitoramento de informações sobre emoções, humores e estados psicológicos dos usuários. A coleta e o compartilhamento desse tipo de dados, no entanto, praticamente não 
é especificada. Somente a política de privacidade do Sanvello cita explicitamente a coleta de informações sobre "humor, objetivos e dados pessoais de saúde" (SANVELLO, 2020, tradução nossa).

Quanto à finalidade da coleta de dados, oito aplicativos alegam que os dados são utilizados para melhorar e personalizar a experiência do usuário e/ou aperfeiçoar os produtos e serviços ofertados. Sete aplicativos citam uso de dados para ferramentas de marketing comportamental ou personalização de anúncios. Alguns especificam finalidades analíticas ${ }^{\mathrm{vi}}$, como: interpretações através da análise das ações e preferências do usuário (Meditopia), medir o desempenho de iniciativas de mercado (Cíngulo) ou gerar relatórios com estatísticas sobre o uso dos serviços (Sanvello). Via de regra, deixam brechas para usos não explicitados nas políticas de privacidade e nos termos de uso. Com relação à possibilidade de uso dos dados para fins de pesquisa acadêmica ou científica, três aplicativos a mencionam: Cíngulo, Meditopia e Fabulous. A Figura 4 apresenta uma síntese da análise sobre coleta, compartilhamento e uso de dados declarados pelos desenvolvedores.

Entre os dados coletados e compartilhados enunciados nos termos de uso e políticas de privacidade, identificamos basicamente dois tipos:

Informações pessoais: nome completo, $e$-mail, telefone, endereço, gênero, fotos subidas ao app, data de nascimento, documento de identificação, dados de acesso em redes sociais. O Sanvello menciona, além desses, que coleta dados referentes a planos de saúde e outros dados pessoais de saúde.

Informações gerais ou de atividade: endereço IP, dispositivo, tipo e versão de browser, páginas visitadas dentro do app, quando e por quanto tempo, quais as funcionalidades mais populares, entre outras, obtidas de modo automatizado, a partir de rastros de interação e que não identificam o usuário pessoalmente.

\begin{tabular}{|c|c|}
\hline Fazem mençăo ao compartilhamento de dados com terceiros & $10 / 10$ \\
\hline Fazem mençăo à coleta de dados identificáveis e/ou informaçŏes pessoais & $08 / 10$ \\
\hline Fazem mençâo à coleta de informaçôes gerais ou informaçôes de atividade & $09 / 10$ \\
\hline Especificam quais dados podem ser compartilhados com terceiros & $02 / 10$ \\
\hline Especificam quais săo os terceiros com quem compartilham dados & $04 / 10$ \\
\hline Enunciam explicitamente que năo coletam dados & $01 / 10$ \\
\hline Fazem mençăo ao compartilhamento de dados para pesquisas acadêmico-científicas & $03 / 10$ \\
\hline $\begin{array}{l}\text { Fazem mençăo ao uso de dados para ferramentas de automatizaçâo de anúncios } \\
\text { e/ou marketing personalizado }\end{array}$ & $07 / 10$ \\
\hline $\begin{array}{l}\text { Alegam que submetem os dados a processos de desidentificaçăo (na forma individual } \\
\text { ou agregada) }\end{array}$ & $02 / 10$ \\
\hline Fazem mençăo explícita à coleta de dados emocionais e/ou psicológicos & $01 / 10$ \\
\hline
\end{tabular}

Figura 4 - Síntese das informações sobre coleta, compartilhamento e uso de dados nos termos de uso e políticas de privacidade Fonte: Elaborado pelos autores.

Como descrito no tópico 2, além da análise dos termos de uso e políticas de privacidade, examinamos a presença de trackers nos arquivos de instalação dos aplicativos. No âmbito dos App Studies, investigar os trackers - literalmente rastrear os rastreadores - é um método exploratório que expõe atores e conexões que costumam permanecer opacos na rede que constitui a economia de dados em que os aplicativos se

vii Finalidades analíticas visam gerar conhecimentos sobre análises de conjuntos de dados. 
capitalizam. Além disso, tal rastreamento permite detectar os tipos de trackers mais recorrentes nos PsiApps e a quem pertencem, dando indícios mais tangíveis acerca dos seus modelos de negócios.

Os trackers podem ser agrupados em diferentes categorias, a partir do tipo de informação que coletam. Neste artigo, utilizamos as categorias sugeridas pela própria ferramenta exodus (2020): Relatório de erros, Analíticos, Criadores de perfil, Identificação, Anúncios, Localização. (tradução nossa). Entre essas categorias, dois grupos se destacaram: os 'trackers de anúncios' e os 'trackers analíticos e de perfilização', correspondentes a 33,3\% e 44\%, respectivamente, dos 75 trackers identificados. Enquanto os primeiros são utilizados para veicular automaticamente anúncios segmentados por públicos-alvo, gerando receita com sua aplicação; o segundo grupo se destina a capturar automaticamente uma série de eventos e dados do usuário, visando a construção de perfis, extração de métricas, segmentação de audiência, análise de comportamento dos usuários, relatórios de desempenho do aplicativo, correlação de eventos etc. (GOOGLE FIREBASE, 2020).

A relevância dos 'trackers de anúncios' e dos de 'análise e perfilização' no ecossistema de dados dos PsiApps fornecem mais algumas pistas sobre o modelo de negócios que integra as dinâmicas econômicas de um capitalismo de vigilância cada vez mais lucrativo e sofisticado (ZUBOFF, 2019). Trata-se de um modelo em que dados comportamentais adquirem cada vez mais relevância e valor, uma vez que estes dados são utilizados para inferir traços, estados e perfis psíquicos e emocionais (BRUNO; BENTES; FALTAY, 2019), em processos de perfilização para anúncios ou para outras finalidades comerciais.

Além dos tipos de trackers mais recorrentes, uma questão fundamental é saber quais são as empresas proprietárias dessas ferramentas de rastreamento. Quem são os terceiros que os termos de uso e políticas de privacidade tratam de modo tão vago? O levantamento realizado via exodus mostrou a presença massiva do Facebook e do Google nesse circuito de captura, compartilhamento e análise de dados, o que nos fornece mais um dado importante sobre os atores e as relações que compõem essa infraestrutura que viemos descrevendo. Na inspeção de nove aplicativos ${ }^{\text {viii }}$, os trackers dessas empresas correspondem, juntos, a 66,6\% do total da utilização de trackers. No infográfico a seguir (Figura 5) é possível visualizar o mapeamento realizado, detalhando os trackers e as permissões de cada aplicativo, bem como a recorrência de cada tracker.

viii Em um dos casos, no aplicativo Monitor de Ansiedade e Humor, a ferramenta não foi capaz de inspecionar os arquivos de instalação - Android Application Pack (APK). 


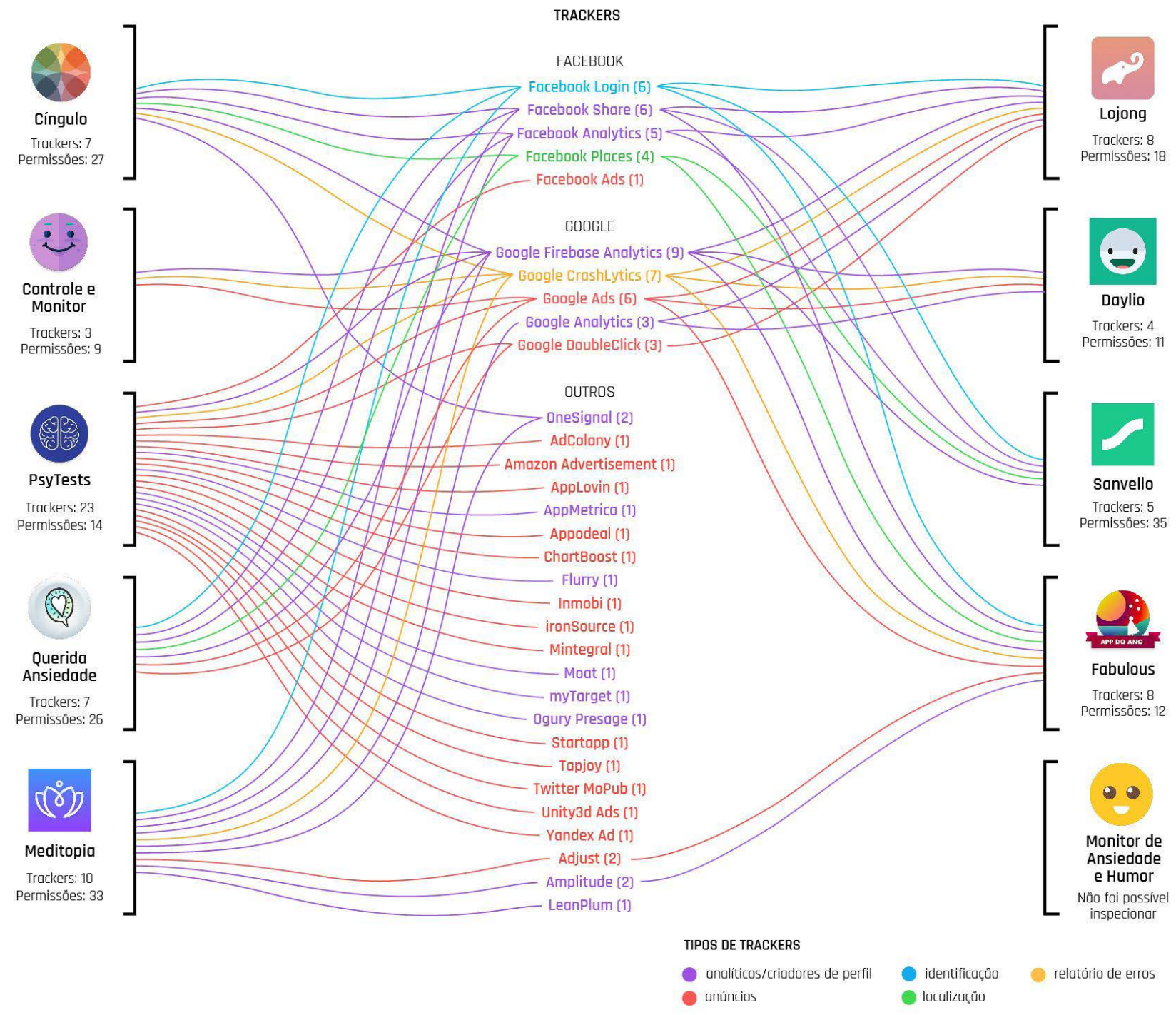

Figura 5 - Trackers por aplicativos detectados pela ferramenta exodus

Fonte: elaborado pelos autores.

Um último aspecto a destacar sobre essa infraestrutura multinível e multiescala é o caráter altamente cíclico, recursivo e performativo de seu funcionamento: os dados capturados, analisados, perfilizados e segmentados são continuamente utilizados para testar, modificar e atualizar os aplicativos, gerando novos dados para análise num 'circuito de retroalimentação' contínuo, para utilizar um termo caro à cibernética (WIENER, 2017; HUI, 2019). Essa performatividade da função recursiva (LURY; DAY, 2019) no ecossistema dos aplicativos é um traço relacionado tanto ao próprio modo de existência dos objetos digitais modulados por algoritmos (HUY, 2016) quanto ao modelo de plataformização (HELMOND, 2015) - que está na base das demandas por contínuas atualizações e inovações do mercado da tecnologia (NIEBORG; POELL, 2018). No infográfico a seguir (Figura 6), ilustramos de modo sintético os fluxos de captura, compartilhamento e análise de dados por meio dos trackers, as múltiplas camadas, os atores e as conexões que compõem a infraestrutura que viemos descrevendo, bem como o caráter cíclico desse processo. 


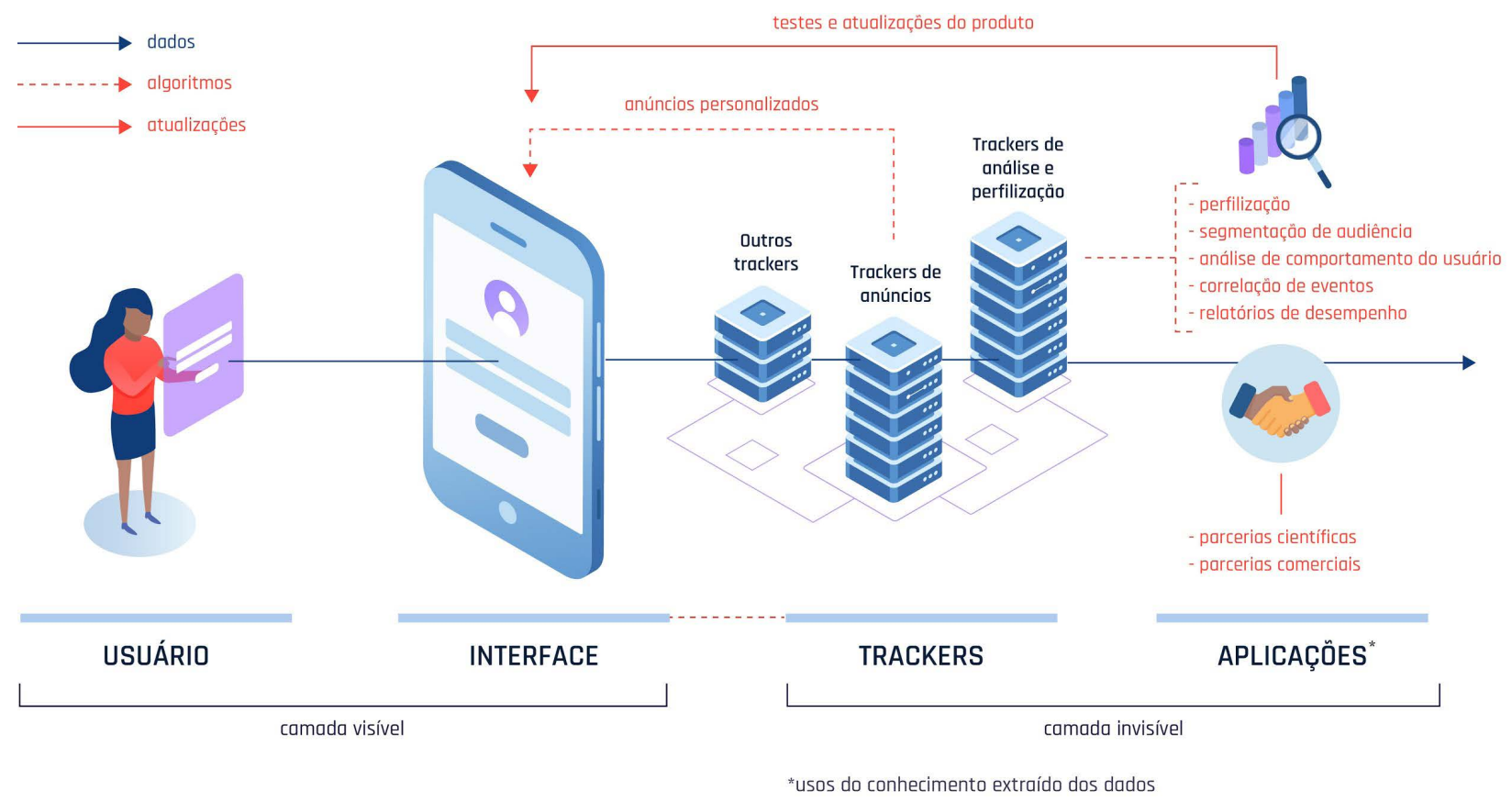

Figura 6 - Fluxo de captura, compartilhamento e análise de dados por meio de trackers Fonte: elaborado pelos autores.

Como se pode ver, o autocuidado, que supostamente colocaria o indivíduo no centro do controle, conta na verdade com uma série de mediadores, humanos e não humanos, que são em grande parte invisíveis para o usuário. Ainda que o app seja visto pelo usuário como um mediador em sua busca por autoconhecimento e autocuidado, os muitos mediadores encapsulados no app escapam ao seu conhecimento e controle.

Ao mesmo tempo, vimos que a infraestrutura por onde trafegam os dados gerados pelo uso do app compõe uma rede heterogênea de relações dinâmicas entre atores, processos, protocolos, finalidades e apropriações, que, mais uma vez, são opacas para os usuários. Apesar de ser parte fundamental dessa infraestrutura composta por atores heterogêneos, o usuário, à diferença dos outros atores que o acompanham e monitoram, desfruta de modo muito limitado da dimensão relacional agenciada nessa rede, uma vez que não participa dela de forma minimamente simétrica. Já os atores que têm acesso privilegiado à infraestrutura e ao ecossistema de dados materializados na camada 'invisível' conseguem, de fato, tirar grande proveito dessa relação.

A dimensão relacional é, assim, quase que inteiramente expropriada por tais atores, que se alimentam dos dados relacionais e produzem perfis, valor, pesquisas científicas, testes e atualizações do produto etc. que constituem-se na verdadeira condição para a possibilidade das ofertas de autonomia da camada 'visível'. O sujeito tem sua participação extremamente limitada nesse processo, uma vez que em grande medida nem se percebe em tal relação, tendo sua agência e margem de negociação bastante reduzidas. É justamente essa limitação e assimetria que o impede de conhecer não só a rede da qual faz parte, mas as implicações de sua falta de autonomia em relação ao ecossistema automatizado.

Como alguns autores vêm destacando, o saber associado à atual economia de dados visa menos um conhecimentoindividualizadoeaprofundado da personalidadedeindivíduos específicos doqueum conhecimento de correlações que revela padrões supraindividuais ou interindividuais que permitam, entre outras finalidades, gerar predições em larga escala (BRUNO; BENTES; FALTAY, 2019; ROUVROY; BERNS, 2015).

Ou seja, apesar de depender da contínua produção, captura e compartilhamento de dados pessoais, a dimensão individual é também no ecossistema de dados, em certa medida, ilusória ou ao menos parcial, ainda que essencial, uma vez que é a dimensão relacional aquela de fato visada por esse modelo de conhecimento e poder. 


\section{CONSIDERAÇÕES FINAIS}

As explorações e comparações entre as dimensões 'visível' e 'invisível', numa via, e individual e relacional, noutra, tornaram explícitas uma série de composições e tensões dos PsiApps e de suas redes sociotécnicas. Por um lado, na camada 'visível', a análise dos objetos, atores e discursos presentes nas interfaces gráficas dos aplicativos e seus canais de divulgação explicitou a reverberação de um discurso neoliberal ancorado na responsabilização do indivíduo, enunciado como oferta de autonomia. Por outro, na camada 'invisível', o rastreamento dos fluxos de captura e compartilhamento de dados dos PsiApps deu visibilidade e materialidade aos mediadores invisíveis e à condição altamente relacional e agenciada dos aplicativos investigados.

O contraste entre a centralidade da agência individual, promovida pelos discursos dos PsiApps, e o caráter extremamente mediado e relacional da infraestrutura e do ecossistema de dados desses aplicativos aponta, assim, para as contradições do modelo de autonomia sintetizado no slogan 'tudo por conta própria'.

É sobretudo a opacidade dessa cadeia de mediadores que faz com que os PsiApps pareçam tecnicamente neutros para os usuários, atuando como "mediações que produzem experiência de não mediação" (CESARINO, 2019, p. 13). O aplicativo e sua suposta neutralidade técnica anuncia-se como um dispositivo perfeito para que cada um monitore, conheça e cuide de si mesmo. Afinal, trata-se de uma máquina que se alimenta de 'nós mesmos' (hábitos, condutas e informações que fornecemos) e que nos devolve uma imagem, um grafo, uma visualização de nosso humor, nossa rotina, nosso nível de ansiedade, nossas noites de sono ou de insônia.

No entanto, sabe-se que "a Ferramenta Neutra sob controle completamente humano" é um mito (LATOUR, 1994, p. 32, tradução nossa). Como vimos, também não são nada neutros os problemas visados pelos apps, assim como as ferramentas que disponibilizam e as soluções que prometem. Embora frequentemente busquem legitimar seus métodos com 'bases científicas', os PsiApps são fruto de uma série de perspectivas sobre o psiquismo, o comportamento e as emoções, bem como sobre suas disfunções e 'aprimoramentos'. Da mesma maneira, os tipos de dados, os hábitos, as emoções e estados psíquicos monitorados e coletados são frutos de escolhas baseadas em abordagens específicas e voltadas para finalidades particulares, as quais não são claras para o usuário, mas não são neutras. Ou seja, os PsiApps estão inseridos numa rede bastante complexa de influências e matrizes sociotécnicas, científicas, econômicas etc. Confrontar os discursos e modelos terapêuticos que colocam o indivíduo no controle do seu autocuidado com a materialidade e heterogeneidade dos atores e conexões agenciados na camada invisível evidenciou não apenas como os aplicativos móveis são parte da infraestrutura de uma poderosa economia de dados que se torna central para o capitalismo contemporâneo, mas também permitiu identificar processos ligados a contextos sociais, políticos e culturais mais amplos. Não por acaso, a defesa do fim dos mediadores tradicionais atravessa o funcionamento neoliberal da sociedade (CESARINO, 2019). Se o indivíduo deve ser o único responsável por sua autorrealização, quanto menos mediadores existirem entre ele e a conquista de suas metas, melhor.

Além disso, o predomínio de técnicas de automonitoramento; que traduzem em dados humores e estados psíquicos são mais um indício do modo de funcionamento da mediação técnica desses dispositivos: eles sugerem como certos modelos terapêuticos podem ser mais adequados não somente à proposta de tratamento rápido, autônomo e flexível, mas às próprias operações técnicas dos aplicativos, sobretudo as algorítmicas. Noutros termos, o privilégio dado a certas ferramentas pelos PsiApps não é apenas indica- 
tivo dos modelos subjetivos e epistemológicos que estão em sua base, mas de quais modelos terapêuticos geram dados legíveis e operacionalizáveis algoritmicamente pela mediação técnica.

Portanto, nessa jornada de autoconhecimento e autocuidado marcadamente neoliberal, o usuário está longe de alcançar efetivamente o modelo de autonomia tão propagado pelos PsiApps. Vimos que os dados gerados por ele são analisados e utilizados por uma série de outros humanos e máquinas, e geralmente compartilhados com terceiros, alimentando um modelo de negócios e de conhecimento dominado pelas grandes corporações de tecnologia. Um ecossistema que visa cada vez mais nossos dados psíquicos e emocionais, mas sobre os quais pouco ou nada sabemos. O promulgado autocuidado é, assim, acompanhado de uma cadeia complexa, heterogênea, recursiva e dinâmica de atores humanos e não humanos, constituída por protocolos tecnológicos, plataformas, instituições, corporações, dispositivos móveis, interfaces, bancos de dados, algoritmos, trackers, cientistas de dados, desenvolvedores, bem como modelos psicológicos, terapêuticos e de negócios. Problematizar tais questões não significa tomar o usuário por ingênuo. Trata-se, contudo, de enfatizar as implicações da assimetria materializada nessa rede sociotécnica entre o usuário e os atores que possuem acesso privilegiado ao ecossistema de dados.

Conforme reordenam a forma como as informações psicológicas são compreendidas, apresentadas e utilizadas, os PsiApps produzem entendimentos e concepções específicos sobre o bem-estar psíquico e emocional. À medida que essas tecnologias são cada vez mais utilizadas e suas funcionalidades se sofisticam, passam a ser reconhecidas como ferramenta privilegiada por meio da qual os sujeitos podem conhecer e cuidar de si mesmos, enquanto permanecem relativamente indefinidos suas implicações e efeitos. É precisamente a partir de uma compreensão crítica dessas implicações e efeitos que se poderá avaliar as potencialidades e armadilhas dos novos cruzamentos entre a automação e o cuidado de si materializados nesses dispositivos.

\section{REFERÊNCIAS}

BRATTON, Benjamin H. The Stack: on software and sovereignty. Cambridge, Londres: MIT Press, 2015.

BROWN, Wendy. American nightmare: neoliberalism, neoconservatism, and de-democratization. Political Theory, [s. I.], v. 34, n. 6, p. 690-714, 2006. DOI: https://doi.org/10.1177\%2F0090591706293016. Disponível em: https://journals.sagepub.com/doi/10.1177/0090591706293016\#articleCitationDownloadContainer. Acesso em: 14 dez. 2020.

BRUNO, Fernanda. A economia psíquica dos algoritmos: quando o laboratório é o mundo. Nexo, São Paulo, 2018. Ensaio. Disponível em: https://www.nexojornal.com.br/ensaio/2018/A-economia-ps\%C3\%ADquica-dosalgoritmos-quando-o-laborat\%C3\%B3rio-\%C3\%A9-o-mundo. Acesso em: 12 ago. 2018.

BRUNO, Fernanda; BENTES, Anna Carolina Franco; FALTAY, Paulo. Economia psíquica dos algoritmos e laboratório de plataforma: mercado, ciência e modulação do comportamento. Revista Famecos, Porto Alegre, v. 26, n. 3, set-dez, 2018, p. e33095. DOI: http://dx.doi.org/10.15448/1980-3729.2019.3.33095. Disponível em: https://revistaseletronicas.pucrs.br/ojs/index.php/revistafamecos/article/view/33095. Acesso em: 01 set. 2020.

CíNGULO. [S. I., 2019]. Twitter: @cinguloapp. Disponível em: https://twitter.com/cinguloapp. Acesso em: 19 set. 2019.

DARDOT, Pierre; LAVAL, Christian. A nova razão do mundo: ensaio sobre a sociedade neoliberal. São Paulo: Boitempo, 2016.

DAUBS, Michael S.; MANZEROLLE, Vincent R. App-centric mobile media and commoditization: Implications for the future of the open Web. Mobile Media \& Communication, [s. I.], v. 4, n. 1, p. 52-68, 2016. DOI: https:// doi.org/10.1177/2050157915592657. isponível em: https://journals.sagepub.com/doi/10.1177/20501579155926 57\#articleCitationDownloadContainer. Acesso em: 01 set. 2020.

DAYLIO - DIARY, JOURNAL, MOOD TRACKER. Bratislava, 2019. Google Play: Daylio - Diary, Journal, Mood Tracker. Disponível em: https://play.google.com/store/apps/details?id=net.daylio. Acesso em: 18 set. 2019. 
DIETER, Michael; GERLITZ, Carolin; HELMOND, Anne; TKACZ, Nathaniel; VLIST, Fernando N. van der; WELTEVREDE, Esther. Multi-Situated App Studies: Methods and Propositions. Social Media + Society, [s. I.], v. 5, n. 2, p. 1-15, abr. 2019. DOI: https://doi.org/10.1177/2056305119846486. Disponível em: https://journals. sagepub.com/doi/10.1177/2056305119846486\#articleCitationDownloadContainer. Acesso em: 01 set. 2020.

EHRENBERG, Alain. O culto da performance: da aventura empreendedora à depressão nervosa. Aparecida: Ideias \& Letras, 2010.

EXODUS. Trackers. [S. I.: s. n.], c2020. Disponível em: https://reports.exodus-privacy.eu.org/en/info/trackers/. Acesso em: 11 abr. 2020.

FABULOUS. Paris, 2019. Google Play: Fabulous: motive-me! Medite, relaxe, durma. Disponível em: https:// play.google.com/store/apps/details?id=co.thefabulous.app\&hl=pt_BR. Acesso em: 19 set. 2019.

FISHER, Mark. Realismo capitalista: no hay alternativa? Buenos Aires: Caja Negra, 2016.

FOUCAULT, Michel. História da sexualidade: o cuidado de si. Rio de Janeiro: Graal, 2002. v. 3.

FOUCAULT, Michel. História da sexualidade: o uso dos prazeres. 13. ed. São Paulo: Graal, 2010. v. 2.

GERLITZ, Carolin; HELMOND, Anne; NIEBORG, David B.; VLIST, Fernando N. van der. Apps and Infrastructures: a Research Agenda. Computational Culture, [s. I.], n. 7, p. 21 out. 2019. Disponível em: http:// computationalculture.net/apps-and-infrastructures-a-research-agendal. Acesso em: 01 set. 2020.

GOOGLE FIREBASE. Google Analytics. [S. I.]: Google, 2020. Disponível em: https://firebase.google.com/ docs/analytics?hl=pt-br. Acesso em: 01 set. 2020.

HELMOND, Anne. The Platformization of the Web: Making Web Data Platform Ready. Social Media + Society, [s. I.], v. 1, n. 2, jul. 2015. DOI: https://doi.org/10.1177/2056305115603080. Disponível em: https://journals. sagepub.com/doi/10.1177/2056305115603080. Acesso em: 04 ago. 2020.

HUI, Yuk. On the existence of digital objects. Minnesota: University of Minnesota Press, 2016. v. 48.

HUI, Yuk. Recursivity and contingency. Lanham: Rowman \& Littlefield Publishers, 2019.

INSTITUTO BRASILEIRO DE COACHING (IBC). O que é coaching?. Goiânia: Instituto Brasileiro de Coaching, 2020. Disponível em: https://www.ibccoaching.com.br/portal/coaching/o-que-e-coaching/. Acesso em: 15 dez. 2020

LATOUR, Bruno. On technical mediation: philosophy, sociology, genealogy. Common Knowledge, [s. I.], v. 3, n. 2, p. 29-64, 1994.

LATOUR, Bruno. Ciência em ação: como seguir cientistas e engenheiros sociedade afora. São Paulo: Ed. Unesp, 2000.

LATOUR, Bruno. Reagregando o social: uma introdução à teoria do ator-rede. Salvador: EdUfba; Bauru: EdUsc, 2012

LAW, John. Notes on the theory of the actor network: ordering, strategy and heterogeneity. Lancaster: Lancaster University. 1992. Disponível em: https://www.lancaster.ac.uk/fass/resources/sociology-online-papers/ papers/law-notes-on-ant.pdf. Acesso em: 07 set. 2020.

LOJONG APP. [S. I., 2019]. Instagram: @applojong. Disponível em: https://www.instagram.com/ applojong/?hl=pt. Acesso em: 18 set. 2019.

LURY, Celia; DAY, Sophie. Algorithmic Personalization as a Mode of Individuation. Theory, Culture \& Society [s. I.], v. 36, n. 2, p. 17-37, jan. 2019. DOI: https://doi.org/10.1177/0263276418818888. Disponível em: https:// journals.sagepub.com/doi/10.1177/0263276418818888\#articleCitationDownloadContainer. Acesso em: 01 set. 2020

MEDEIROS, Henrique. Instalações de aplicativos de saúde crescem 226\% no Brasil, diz AppsFlyer. Mobile Time, [s. I.]: Mobile Time, 27 mar. 2020. Disponível em: https://www.mobiletime.com.br/noticias/27/03/2020/ aplicativos-de-saude-crescem-226-em-instalacoes-no-brasil-diz-appsflyerl. Acesso em: 27 mar. 2020. 
MONITOR DE ANSIEDADE E HUMOR. Fortaleza, 2019. Google Play: Monitor de ansiedade e humor. Disponível em: https://play.google.com/store/apps/details?id=br.com.delxmobile.ansiedade. Acesso em: 18 set. 2019.

MORAES, Maria Regina Cariello. O desencantamento da meditação: da união mística ao fitness cerebral. Religião \& Sociedade, Rio de Janeiro, v. 39, n. 1, p. 224-248, maio 2019. DOI: https://doi.org/10.1590/010085872019v39n1cap10. Disponível em: https://www.scielo.br/scielo.php?script=sci arttext\&pid=S010085872019000100224\&tIng=pt. Acesso em: 01 set. 2020.

NASCIMENTO, Liliane da Costa. 0 autoconhecimento através dos números: as práticas de automonitoramento dos quantified selves. 2014. 355 f. Tese (Doutorado em Comunicação e Cultura) - Rio de Janeiro: Universidade Federal do Rio de Janeiro, 2014.

NELSON, Alondra. Body and soul: the Black Panther Party and the fight against medical discrimination. Minnesota: University of Minnesota Press, 2011.

NIEBORG, David B.; POELL, Thomas. The platformization of cultural production: theorizing the contingent cultural commodity. New Media \& Society, [s. I.], v. 20, n. 11, p. 4.275-4.292, 2018. DOI: https://doi. org/10.1177/1461444818769694. Disponível em: https://journals.sagepub.com/doi/10.1177/146144481876969 4\#articleCitationDownloadContainer. Acesso em: 01 set. 2020.

PANORAMA MOBILETIME. Uso de apps no Brasil + Guia de serviços para apps - Junho de 2019. [S. I.: s. n., 2019]. Disponível em: https://panoramamobiletime.com.br/pesquisa-uso-de-apps-junho-de-2019/. Acesso em: 25 abr. 2020.

PASQUALE, Frank. The black box society: the secret algorithms that control money and information. Cambridge: Harvard University Press, 2015.

PLAY CONSOLE AJUDA. Escolha uma categoria e etiquetas para a sua app ou jogo. [S. I.]: Google, c2020. Disponível em: https://support.google.com/googleplay/android-developer/answer/113475?hl=pt. Acesso em: 07 set. 2020.

PURSER, Ronald. Mindfulness entre racionalidade empreendedora e violência epistêmica: entrevista com Ronald Purser. DigiLabour, [s. I.], 06. dez. 2019. Disponível em: https://digilabour.com.br/2019/12/06/ mindfulness-entre-racionalidade-empreendedora-e-violencia-epistemica-entrevista-com-ronald-purser. Acesso em: 05 maio 2020.

QUERIDA ANSIEDADE. Site oficial. [S. I.: s. n.], c2020. Disponível em: https://www.queridaansiedade.com.br. Acesso em: 01 set. 2020.

QUERIDA ANSIEDADE. [S. I.], 2019. Google Play: Querida Ansiedade. Disponível em: https://play.google.com/ store/apps/details?id=br.com.app.gpu1622660.gpu9b5c43256d3faa5c3ad1ef7369f09620\&hl=pt_BR. Acesso em: 18 set. 2019.

QUERIDA ANSIEDADE. [S. I., 2019]. Instagram: @queridaansiedade.com.br. Disponível em: https://www. instagram.com/queridaansiedade.com.br/?hl=pt-br. Acesso em: 18 set. 2019.

ROSE, Nikolas. Inventando nossos selfs: psicologia, poder e subjetividade. Petrópolis: Vozes, 2011.

ROUVROY, Antoinette; BERNS, Thomas. Governamentalidade algorítmica e perspectivas de emancipação: o díspar como condição de individuação pela relação?. Revista Eco-Pós, Rio de Janeiro, v. 18, n. 2, 2015, p. 36-56. Disponível em: https://revistas.ufrj.br/index.php/eco pos/article/view/2662. Acesso em: 01 set. 2020.

SANVELLO. Online services privacy policy. [S. I.]: Sanvelo Health, 2020. Disponível em: https://www. sanvello.com/privacy-policyl. Acesso em: 01 set. 2020.

SRNICEK, Nick. Platform Capitalism. Malden: Polity Press, 2017.

TOROUS, John; NICHOLAS, Jennifer; LARSEN, Mark E.; FIRTH, Joseph; CHRISTENSE, Helen. Clinical review of user engagement with mental health smartphone apps: evidence, theory and improvements. Evidence-Based Mental Health, [s. I.], v. 21, n. 3, 2018, p. 116-119. DOI: https://doi.org/10.1136/eb-2018102891. Disponível em: https://ebmh.bmj.com/content/21/3/116. Acesso em: 01 set. 2020. 
Reciis - Revista Eletrônica de Comunicação, Informação \& Inovação em Saúde, Rio de Janeiro, v. 15, n. 1, p. 33-54, jan./mar. 2021 [www.reciis.icict.fiocruz.br] e-ISSN 1981-6278

WORLD HEATH ORGANIZATION (WHO). Mental health and COVID-19. Copenhagen: WHO, c2021.

Disponível em: https://www.euro.who.int/en/health-topics/noncommunicable-diseases/mental-health/data-andresources/mental-health-and-covid-19. Acesso em: 14 mai. 2020.

WORLD HEATH ORGANIZATION (WHO). Depression and other common mental disorders: global health estimates. [Copenhagen]: WHO, 2017. E-book. Disponível em: https://apps.who.int/iris/handle/10665/254610. Acesso em: 20 ago. 2020.

WIENER, Norbet. Cibernética: ou controle e comunicação no animal e na máquina. São Paulo: Perspectiva, 2017.

ZITTRAIN, Jonathan. The future of the Internet: and how to stop it. New Haven: Yale University Press, 2008.

ZUBOFF, Shoshana. The age of surveillance capitalism: the fight for a human future at the new frontier of power. Nova York: Public Affairs, 2019. 